\title{
Youth labour markets in Spain: Education, training, and crowding-out $\equiv$
}

\author{
Juan J. Dolado ${ }^{\mathrm{a}, \mathrm{b}}$, Florentino Felgueroso ${ }^{\mathrm{c}}$, \\ Juan F. Jimeno ${ }^{\mathrm{b}, \mathrm{d}, \mathrm{e}, *}$ \\ ${ }^{a}$ Universidad Carlos III de Madrid, Madrid, Spain \\ ${ }^{\mathrm{b}}$ Centre for Economic Policy Research, London, UK \\ ${ }^{\mathrm{c}}$ Universidad de Oviedo, Oviedo, Spain \\ 'Universidad de Alcalá, Madrid, Spain \\ ${ }^{\mathrm{e}}$ FEDEA, Madrid, Spain
}

\begin{abstract}
The stylised facts describing the poor performance of the youth labour market in Spain over the last two decades, entailing high unemployment rates for both higher and lower educated workers, over-education and low intensity of on-the-job training, are explained through a simple matching model where higher educated workers crowd-out lower educated ones from their traditional entry jobs. In this model, a combination of rigid labour market institutions and an increase in the relative supply of higher educated workers harms the training prospects of lower educated workers. (C) 2000 Elsevier Science B.V. All rights reserved.
\end{abstract}

JEL classification: J21; J23.

Keywords: Unemployment; Education; Training; Matching

\section{Introduction}

Spanish unemployment, besides being very high and persistent, is very unevenly distributed: female and youth unemployment rates have been about 10 and 20 percentage points higher, respectively, than the average unemployment

\footnotetext{
* Corresponding author. FEDEA, Jorge Juan 46, 28001 Madrid, Spain. Tel.: 34-1-4350401; fax: 34-1-5779575.

E-mail address: jimeno@fedea.es (J.F. Jimeno)
} 
rate, close to $20 \%$ since the mid-1980s. This fact constitutes a puzzle considering that in the last 50 years there has been a very rapid educational upgrading which has mostly affected precisely females and young workers.

The educational drive in Spain has taken place at a time when skill-biased technological progress and increased global competition were leading to a change in the industrial structure and a fall in the demand of lower educated workers. However, in a companion paper (Dolado et al., 1999) we have argued that both forces, on their own, cannot explain the various stylized facts which have been observed in Spain. Indeed, in addition to the explanations just mentioned above, we argued that there is the less familiar explanation of 'crowding out' of workers with lower education by those with a higher education. In some European countries, recent studies (see Muysken and Ter Weel (1998) and the references therein) are rediscovering the old concept of overeducation to explain unemployment differentials by educational levels.

Traditionally, job competition and crowding-out models stem from the existence of training ladders and a given amount of jobs with fixed characteristics (see Thurow, 1975) or from situations when firms find it costly to adjust wages and thus react by increasing hiring standards instead (see Okun, 1981). An alternative explanation for 'crowding out' could be given by standard search theory (see Van Ours and Ridder, 1995). According to the latter, when it takes time for workers and vacancies to find each other, a possible strategy for higher educated workers is to accept a temporary unskilled job and to continue searching for a skilled job paying a higher wage.

Five stylized facts characterise the performance of Spanish youth labour market over the last two decades:

1. The rise of unemployment rates has been primarily concentrated in lower educated workers but it has also taken place for higher educated ones.

2. The effects of educational attainments on the employment rate are not particularly large. For instance, it is only after 30 years of age that workers with a university degree have lower unemployment rates than workers with high school or with a college diploma.

3. There is a dramatic downgrading in the entry-jobs market which affects mainly the workers aged between 16 and 27 years of age and all educational attainments. This downgrading seems to have harmed the employability of workers with low levels of educational attainments.

4. There is a deceleration in the return to schooling (see e.g. Alba, 1993). Relative wages for educated workers have, if anything, become stagnant over the last decade.

5. The amount of on-the-job training provided by firms to lower educated workers is seemingly rather low. Thus, these workers hold entry jobs which provide many less opportunities of promotion in the future than they used to do in the past. 
We address the issue of whether a matching model, as in Mortensen and Pissarides (1994) and Pissarides (1994), with a non-segmented structure can account for these facts. In our model there are two types of jobs (skilled and unskilled) and two types of workers (higher and lower educated). We assume that hires take place in a non-segmented labour market where higher educated workers can perform unskilled jobs but less educated workers cannot perform skilled jobs.

In Dolado et al. (1999) we use this model to explain issues 1-4 listed above. We found that the model was able to explain these four stylized facts when combined with increases in the separation rate, in non-working benefits and in union power. ${ }^{1}$ In this paper, we concentrate on the fifth fact, namely that regarding the consequences of crowding out on training. We argue that the increase in the relative supply of educated workers has harmed the on-the-job training prospects for less educated workers.

The structure of the rest of the paper is as follows. Section 2 documents the stylized facts motivating the paper, Section 3 presents the theoretical framework, and Section 4 contains some final remarks.

\section{Facts}

\subsection{Educational attainments by age and gender}

Starting in the 1960s from one of the lowest stocks of human capital in the OECD $(8 \%$ of the population aged $10-14$ and $40 \%$ of those above 65 were illiterate), Spain has experienced a remarkable improvement in the relative supply of educated workers. An important characteristic of this process is that the emphasis has been towards higher educational levels (essentially university/tertiary degrees) and that, to a large extent, it has been reinforced by a steady rise in the female demand for formal education.

These features are illustrated in the three panels of Table 1. In panel (a) there is a comparison of educational attainments of population aged 25-64 in Spain and the OECD, as of 1995. While Spain has one of the largest shares of population with at most upper secondary education, the youngest cohorts (25-34 years of age) are between twice and four times more educated than older cohorts. Panel (b) shows how this higher education is mostly concentrated on female workers,

\footnotetext{
${ }^{1}$ Both conditions are not at odds with the recent evolution of the Spanish labour market. The liberalizarion of fixed-term jobs in 1984 has produced a drastic increase in the workers turnover rate and, hence, a rise in the separation rate (see Bentolila and Dolado, 1994). Likewise, it is likely that despite the declining density of the Spanish unions, their coverage has increased over the last two decades. Finally, the coverage and generosity of unemployment benefits also increased throughout the 1980s.
} 
Table 1

Education and unemployment in Spain

Panel (a). Educational attainment by age group

\begin{tabular}{|c|c|c|c|c|c|c|c|c|}
\hline & \multicolumn{2}{|c|}{ 25-64 years } & \multicolumn{2}{|c|}{$25-34 / 35-44$ years } & \multicolumn{2}{|c|}{$25-34 / 45-54$ years } & \multicolumn{2}{|c|}{$25-34 / 55-64$ years } \\
\hline & $U^{a}{ }^{a}$ & $\mathrm{U}^{\mathrm{a}}$ & US & $\mathrm{U}$ & US & $\mathrm{U}$ & US & $\mathrm{U}$ \\
\hline Spain & 28 & 16 & 1.5 & 1.5 & 2.6 & 2.5 & 4.7 & 4.5 \\
\hline OECD & 60 & 22 & 1.1 & 1.0 & 1.3 & 1.3 & 1.7 & 1.9 \\
\hline
\end{tabular}

Panel (b). Educational attainment of school leavers among population aged 16-29 years

\begin{tabular}{llllll}
\hline & \multicolumn{3}{l}{ Males } & & \multicolumn{2}{l}{ Females } \\
\cline { 2 - 3 } \cline { 5 - 6 } & LS $^{\mathrm{a}}$ & $\mathrm{U}$ & & LS & U \\
\cline { 2 - 3 } & 44 & 25 & & 23 & 39 \\
Spain & 36 & 23 & & 31 & 26 \\
\hline
\end{tabular}

Panel (c). Unemployment rates (\%) by age and educational attainment

\begin{tabular}{|c|c|c|c|c|c|c|c|c|c|}
\hline & \multicolumn{3}{|c|}{$20-24$ years of age } & \multicolumn{3}{|c|}{$25-29$ years of age } & \multicolumn{3}{|c|}{$29-64$ years of age } \\
\hline & LS & US & $\mathrm{U}$ & LS & US & $\mathrm{U}$ & LS & US & $\mathrm{U}$ \\
\hline Spain & 37.4 & 41.0 & 53.1 & 32.3 & 27.0 & 33.2 & 20.6 & 18.5 & 13.5 \\
\hline OECD & 21.9 & 15.5 & 15.3 & 16.9 & 9.8 & 8.5 & 10.1 & 7.0 & 4.0 \\
\hline
\end{tabular}

${ }^{a}$ LS: lower secondary or less, US: upper secondary, U: university.

Notes: Column 1 of panel (a) gives the proportion (in \%) of population 25-64 years of age who have completed at least upper secondary or university education. The remaining columns give the ratios between these proportions for different age cohorts (Source: OECD, 1997). Panel (b) gives the proportion (in \%) of the population of school leavers with lower secondary education or less and university education (Source: OECD, 1998). Panel (c): Source: OECD (1997).

contrary to what happens in the OECD. Finally, panel (c) shows unemployment rates by age and educational attainments. It can be observed that the standard negative relationship between education and unemployment in the OECD is less pronounced in Spain. Notwithstanding, the evolution of unemployment between 1977 and 1998 is more unfavorable for workers with lower secondary education - a rise from $2 \%(3 \%)$ to $17 \%(32 \%)$ for $25-39$ aged male (female) workers, than for those with a university degree - a rise from $2 \%(3 \%)$ to $13 \%(21 \%)$ for the same age cohort. 


\subsection{Entry jobs}

Over the last two decades, there is a tendency towards the less skilled jobs being occupied by the more educated workers. We illustrate this phenomenon by making use of the occupational structure of the so-called 'entry-jobs' into the labour market, namely the type of jobs that youth workers take after completing a given educational level and which are supposed to provide training and promotion possibilities in the future. For that purpose, four age groups and four educational levels have been chosen in such a way that it allows us to describe the kind of job that young workers were occupying up to four years since they finished their studies. Hence, the 16-20 cohort corresponds to compulsory lower education, 18-22 to upper secondary education, 21-25 to college diploma and 23-27 to university degree. As regards occupations, we consider Professionals/Technicals (P1); Teaching Professionals and Employees in Public Administration (P2); Clericals and Administratives (P3); Manual Crafts and Operators (P4), and Sales Elementary and Hotel \& Restaurant Occupations, Unskilled Services and Labourers (P5). The five occupations have been ranked in decreasing order of skill requirements for the job. The inclusion of P2 is justified since accession to Public Administration, through several types of competitions, has been a traditional 'entry job' for Spanish youth workers, either with a high or an intermediate level of education.

For the three main occupational groups described above, and for age cohorts and educational attainments, Fig. 1 plots the proportion of the corresponding occupation in male employment (dotted lines) and the proportion of male wage earners with a given age and educational attainment who work in a certain occupation (solid lines). The lesson to be drawn from this figure is that the more educated workers seem to be increasingly filling both the more skilled jobs (P1) and the semi-skilled ones (P3). This process is taking place at the expense of a drastic reduction in $\mathrm{P} 2$, possibly due to the ageing of the Public Administration employees and/or the lack of hiring of young workers. At the same time the less educated workers have been crowded out from their traditional 'entry-jobs', namely semi-skilled jobs (P3) towards those jobs that hardly offer any training and require no educational qualifications (P5). ${ }^{2}$

\subsection{Overeducation and training}

One possibility could be that the IT revolution has changed so much the education requirements of the occupations we have considered that both overeducation and crowding-out of low-educated workers are only apparent phenomena. We look at workers' perception of educational requirements for

\footnotetext{
${ }^{2}$ Similar findings also apply to female workers (see Dolado et al., 1999).
} 
A. Lower secondary education or less, $16-20$ year-olds
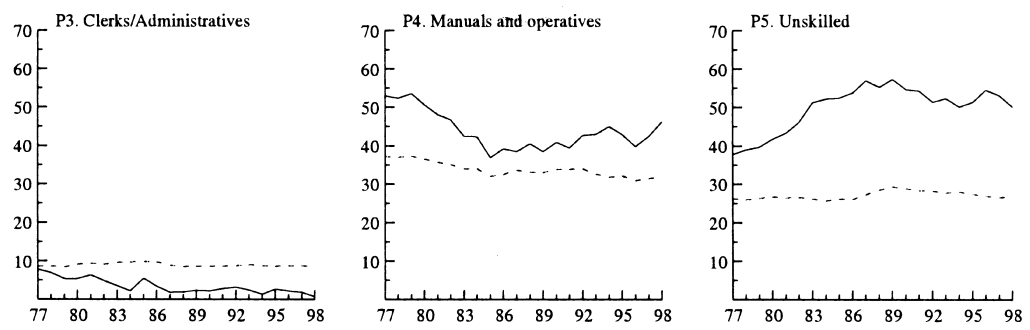

B. Upper secondary education (except vocational), 18-22 year-olds
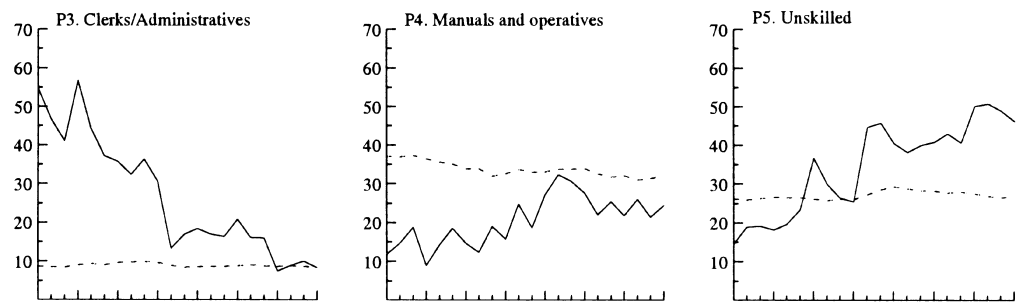

C. College diploma/University $1^{\circ}$ degree, 21-25 year-olds
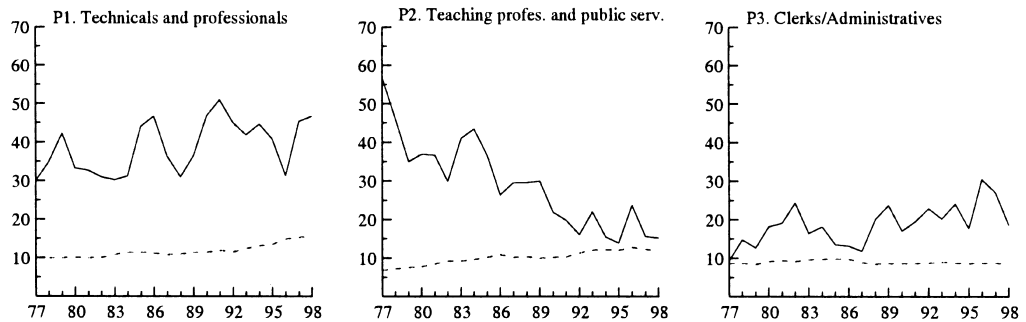

D. University $\left(2^{\circ}\right)$ degree, 23-27 year-olds
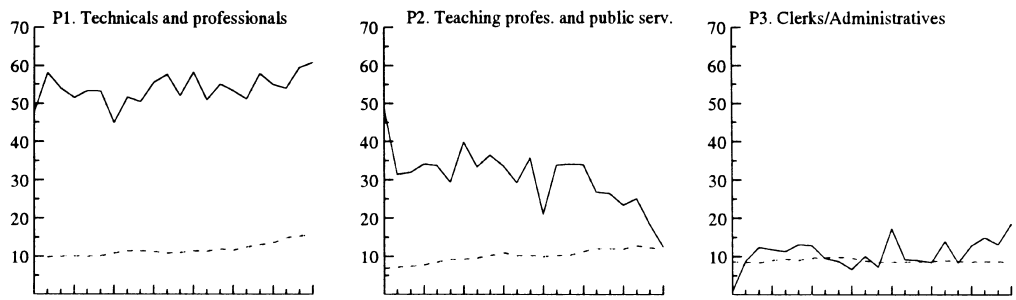

Fig. 1. Entry jobs by age and education, men (1977-1998). 
Table 2

Overeducation and training in Spain

\begin{tabular}{|c|c|c|c|c|c|c|c|c|}
\hline \multirow[t]{2}{*}{ Ed. Att./Occup. } & \multicolumn{2}{|l|}{$\mathrm{P} 1$} & \multicolumn{2}{|c|}{$\mathrm{P} 2$} & \multicolumn{2}{|l|}{ P3 } & \multicolumn{2}{|c|}{ P4 \& P5 } \\
\hline & $\mathrm{O}^{\mathrm{a}}$ & $\mathrm{U}^{\mathrm{a}}$ & $\mathrm{O}$ & $\mathrm{U}$ & $\mathrm{O}$ & $\mathrm{U}$ & $\mathrm{O}$ & $\mathrm{U}$ \\
\hline
\end{tabular}

(a) Workers' perception of over- and underqualification (\%)

$\begin{array}{lllllllll}\text { Lower education } & 33.3 & 66.7 & 16.7 & 44.4 & 12.5 & 66.7 & 34.2 & 31.6 \\ \text { Secondary education } & 23.1 & 46.2 & 41.2 & 23.5 & 17.6 & 49.0 & 55.0 & 23.3 \\ \text { Vocational training } & 15.6 & 71.9 & 27.0 & 40.5 & 15.0 & 68.3 & 53.0 & 33.9 \\ \text { Tert./univ. education } & 23.5 & 69.1 & 25.3 & 60.0 & 74.5 & 21.3 & 80.0 & 10.0\end{array}$

(b) Workers receiving on-the-job training $(\%)$

$\begin{array}{llllc}\text { Lower education } & 0 & 40 & 33.3 & 13 \\ \text { Secondary education } & 33.3 & 33.3 & 47.6 & 9.1 \\ \text { Vocational training } & 68.6 & 28.6 & 33.3 & 27 \\ \text { Tert./univ. education } & 50.0 & 25 & 22.2 & 11.1\end{array}$

${ }^{a}$ O: overqualified, U: underqualified. Source: EUROSTAT Household Panel Survey.

a given occupation First, panel (a) of Table 2 shows the proportion of workers under 30 years of age who declare to be overqualified in their current jobs. When we distinguish by educational attaintment and occupation, the proportion of workers in P3 with tertiary/university education who declare to be overqualified is close to $75 \%$, while most workers with lower educational attaintments declare to be underqualified. Indeed, the pattern of responses for P3 is different from those pertaining to the remaining occupations where under- and overqualification hold for P1 and P2 and for P4 and P5, respectively. This seems to indicate that higher educated workers do have enough human capital to hold P3 jobs, whereas less educated workers do not and thus specific training is needed. Without past observations on workers' perceptions of jobs' educational requirements, we cannot be sure about recent trends in overeducation stemming from the IT revolution. However, it seems clear that a significant proportion of higher educated workers in semi-skilled jobs declared themselves to be overqualified for those jobs.

As regards training, a few words about how it is provided in Spain are in order. In general, there are school-based and workplace-based systems, the latter either based on firm skill formation or on government-led programs (see OECD, 1998). The Spanish system is mainly school-based and relies on employer subsidies or tax relief conditional on work-place training through special training/apprenticeship systems aimed at youth. However, apprenticeship employment contracts only accounted for $12 \%$ of youth employment in 1995 given the high incidence of fixed-term employment contracts which do not involve any explicit training altogether (see Bentolila and Dolado, 1994). Moreover, despite 
generous incentives to convert fixed-term into permanent contracts, only $12 \%$ of training contracts and $28 \%$ of apprenticeship contracts were so converted in 1997. Panel (b) of Table 2 gives the proportion of workers whose training has been provided and paid by the firm, broken down by the worker's educational attaintment and occupation, as reported by the European Household Panel Survey (HPS). It is noteworthy that this fraction in P3 is highest for workers with upper-secondary education and lowest for workers with tertiary/university education. Indeed, though not reported here for the sake of brevity, we find, using individual data from the HPS, that the probability that a higher educated worker occupies a job in P3 increases with the regional unemployment rates of educated worker and the minimum wages set for those occupations by the provincial/sectoral collective wage bargaining agreements (see Dolado et al., 1997). Moreover, less training for lower educated workers is provided when employment conditions are set by collective bargaining agreements at the industry level than when employment conditions are set by firm level collective agreements.

\section{A matching model}

To account for overeducation, training and crowding-out, we consider a simple matching model with two types of workers - educated and noneducated, two types of jobs - skilled and unskilled, and on-the-job search for educated workers employed in unskilled jobs. ${ }^{3}$ There is a continuum of firms. Unskilled jobs do not require any schooling but skilled jobs can only be filled by educated workers, who also can take unskilled jobs. The supply of non-educated and educated workers is exogenously given and equal to $L_{1}$ and $L_{2}$, respectively ( $\kappa=L_{2} / L_{1}$ is the ratio of educated to non-educated workers). ${ }^{4}$ Training in the firm is required for non-educated workers and is not a substitute for schooling. Firms post vacancies for unskilled and skilled jobs. Educated workers will accept offers for unskilled jobs if they do not have offers for skilled jobs and the value from being employed in an unskilled job is larger than the valued of being unemployed. Firms will hire educated workers for unskilled jobs as this implies saving of the training costs required for non-educated workers. Firms do not discriminate against educated workers occupying unskilled jobs (there is no bad

\footnotetext{
${ }^{3}$ It departs from other models in the search literature with heterogeneous workers (see for instance, Brunello, 1996; Saint-Paul, 1996; Acemoglu, 1997; Mortensen and Pissarides, 1998) by assuming that the markets are non-segmented by skills, so that educated workers can be employed in unskilled jobs. In an independent work, Gautier (1999) uses a somewhat similar model to discuss under which conditions low-skilled workers are harmed by competition from skilled workers.

${ }^{4}$ Given the very rapid increase in subsidies for tertiary education which took place in Spain since the early 1980s, this seems an acceptable assumption.
} 
signal in an educated worker taking unskilled jobs) and, in equilibrium, will be indifferent between hiring any type of worker for unskilled jobs.

\subsection{Matching}

Hires are given by matching functions which take the number of searchers and job vacancies as arguments. Educated workers search for skilled jobs and fill them according to the matching function $H_{2}=m\left(u_{2} L_{2}+e_{1}^{2} L_{2}, v_{2} L_{2}\right)$, where $H_{2}$ is the number of hires of educated workers for skilled jobs, $u_{2}$ is the unemployment rate of educated workers, $e_{1}^{2}$ is the proportion of educated workers employed in unskilled jobs who are also assumed to be searching for skilled jobs, $v_{2}$ is the vacancy rate of skilled jobs (measured with respect to $L_{2}$ ), and $m$ is a constant-returns-to-scale (CRS) matching function with $m_{1}, m_{2}>0 .{ }^{5}$ Unemployed educated workers also match with unskilled job vacancies. Given the matching function for skilled jobs, the number of hires of educated workers for unskilled jobs is $H_{1}^{2}=m\left(u_{2} L_{2}, v_{1} L_{1}+v_{2} L_{2}\right)$ $-\left(u_{2} /\left(u_{2}+e_{1}^{2}\right)\right) m\left(u_{2} L_{2}+e_{1}^{2} L_{2}, v_{2} L_{2}\right)$, where $v_{1}$ is the vacancy rate of unskilled jobs (measured with respect to $L_{1}$ ). Finally, for non-educated workers, the number of hires is $H_{1}=m\left(u_{1} L_{1}+u_{2} L_{2}, v_{1} L_{1}\right)-H_{1}^{2}-\left(u_{2} /\left(u_{2}+e_{1}^{2}\right)\right)$ $H_{2}=m\left(u_{1} L_{1}+u_{2} L_{2}, v_{1} L_{1}\right)-m\left(u_{2} L_{2}, v_{1} L_{1}+v_{2} L_{2}\right), u_{1}$ being the unemployment rate of non-educated workers.

Given the matching process, the probabilities of filling vacancies are given by:

- For a skilled job: $q_{2}=H_{2} / v_{2} L_{2}$, which under the CRS assumption can be written as $q_{2}=m\left(\theta_{2}\right)$, with $\theta_{2}=v_{2} /\left(u_{2}+e_{1}^{2}\right)$.

- For unskilled jobs: $q_{1}=\left(H_{1}+H_{1}^{2}\right) / v_{1} L_{1}$, which under the same assumption is equal to $q_{1}=m\left(\theta_{1}\right)-\left(\kappa u_{2} / v_{1}\right) \theta_{2} q_{2}$, with $\theta_{1}=v_{1} /\left(u_{1}+\kappa u_{2}\right)$.

As for workers, the rates at which they receive job offers are

- Skilled job offers for educated workers (either unemployed or employed in unskilled jobs), $\tau_{2}=\theta_{2} q_{2}$.

- Unskilled job offers for educated workers, $\tau_{1}^{2}=\theta_{12} m\left(\theta_{12}\right)-\theta_{2} q_{2}$, with $\theta_{12}=\left(v_{1}+\kappa v_{2}\right) / \kappa u_{2}$.

- Unskilled job offers for non-educated workers, $\tau_{1}=\left(\left(u_{1}+\kappa u_{2}\right) / u_{1}\right) \theta_{1} m\left(\theta_{1}\right)-$ $\left(\kappa u_{2} / u_{1}\right) \theta_{12} m\left(\theta_{12}\right)$.

Thus, as the skilled jobs market gets tighter ( $\theta_{2}$ increases), the proportion of educated workers moving to unskilled jobs decreases, and the proportion of non-educated workers finding unskilled jobs increases.

\footnotetext{
${ }^{5} \mathrm{We}$ are assuming that on-the-job search of educated workers in unskilled jobs is as efficient as the search of unemployed educated workers.
} 


\subsection{Steady-state equilibrium}

In the steady-state equilibrium, the flow out of unemployment and the flow into unemployment are equal for both types of workers and the flow of educated workers into unskilled employment must be equal to the flow of educated workers out of unskilled employment toward unemployment or to skilled employment. Thus, we have: $s_{1} N_{1}^{\mathrm{E}}=\tau_{1} N_{1}^{\mathrm{U}}, s_{2} N_{2}^{\mathrm{E}}=\left(\theta_{2} q_{2}+\tau_{1}^{2}\right) N_{2}^{\mathrm{U}}$, and $\left(s_{1}+\theta_{2} q_{2}\right) N_{2}^{\mathrm{E} 1}=\tau_{1}^{2} N_{2}^{\mathrm{U}}$ where $N_{i}^{\mathrm{E}}\left(N_{i}^{\mathrm{U}}\right)$ is the number of employed (unemployed) workers of type $i(i=1,2), s_{i}$ is the separation rate for jobs of type $i$, and $N_{2}^{\mathrm{E} 1}$ is the number of educated workers in unskilled jobs. Hence, the steady-state unemployment rate for each non-educated worker is

$$
u_{1}=\frac{s_{1}}{s_{1}+\tau_{1}}
$$

the steady-state unemployment rate of educated workers is

$$
u_{2}=\frac{s_{2}}{s_{2}+\theta_{12} m\left(\theta_{12}\right)}
$$

and the proportion of educated workers in unskilled jobs is

$$
e_{1}^{2}=\frac{s_{2}}{s_{1}+\theta_{2} q\left(\theta_{2}\right)}-\frac{s_{2}+\theta_{2} q\left(\theta_{2}\right)}{s_{1}+\theta_{2} q\left(\theta_{2}\right)} u_{2} .
$$

\subsection{The supply of vacancies}

For the determination of the supply of vacancies, we follow Pissarides (1990). Let $V_{i}$ be the returns to opening a job position of type $i(i=1,2), J_{i}$ the asset value of a job of type $i$ filled by a worker of type $i$, and $J_{1}^{2}$ the value of an unskilled job filled by an educated worker. Assuming that $J_{1}=J_{1}^{2}$ we have that $^{6}$

$$
r V_{1}=-\gamma_{1}+q_{1}\left(J_{1}-V_{1}\right)
$$

while for skilled jobs

$$
r V_{2}=-\gamma_{2}+q_{2}\left(J_{2}-V_{2}\right) .
$$

The asset values of a filled job, in turn, are given by

$$
\begin{aligned}
& r J_{1}=y_{1}-w_{1}-t+s_{1}\left(V_{1}-J_{1}\right), \\
& r J_{2}=y_{2}-w_{2}+s_{2}\left(V_{2}-J_{2}\right),
\end{aligned}
$$

\footnotetext{
${ }^{6}$ This assumption is consistent with the matching process specified above and, moreover, guarantees an interior solution for $u_{1}$ and $u_{2}$.
} 
where $r$ is the rate of interest, $\gamma_{i}$ is the cost of keeping a job vacancy of type $i$ unfilled, $y_{i}$ is the output produced by a worker of type $i$ in a job of the same type, $w_{i}$ is the wage paid to workers of type $i$, and $t$ is the training cost for unskilled workers; while for unskilled jobs filled by educated workers ${ }^{7}$

$$
r J_{1}^{2}=y_{1}-w_{1}+\left(s_{1}+\theta_{2} q_{2}\right)\left(V_{1}-J_{1}^{2}\right) .
$$

In equilibrium, all profits opportunities from offering new jobs are exploited so that $V_{1}=V_{2}=0$, and, hence,

$$
J_{1}=\frac{y_{1}-w_{1}-t}{r+s_{1}}, \quad J_{2}=\frac{y_{1}-w_{2}}{r+s_{2}}, \quad J_{1}^{2}=\frac{y_{1}-w_{1}}{r+s_{1}+\theta_{2} q_{2}} .
$$

As for wages, we assume that for educated workers they are equal to a proportion $\beta$ of the total surplus generated by the match, unless outside options of the firm and of the worker are binding (see Acemoglu, 1995) and that these options are not binding, while for non-educated workers we will assume that the outside option of the workers is binding, $z$ being the reservation wage of non-educated workers. Thus,

$$
w_{1}=z, \quad w_{2}=\beta y_{2} .
$$

From Eqs. (4)-(6), after substituting for wages, we get the conditions which represent the supply of vacancies:

$$
\begin{aligned}
& (1-\beta) y_{2} q_{2}=\gamma_{2}\left(r+s_{2}\right), \\
& \left(y_{1}-z\right) q_{1}=\gamma_{1}\left(r+s_{1}+\theta_{2} q_{2}\right),
\end{aligned}
$$

and for the training costs which make firms indifferent between hiring educated or non-educated workers for unskilled jobs

$$
t=\frac{\theta_{2} q_{2}}{r+s_{1}+\theta_{2} q_{2}}\left(y_{1}-z\right)
$$

Thus, as the skilled job market is less tighter and the separation rate in the unskilled job market increases, the training costs which make firms indifferent between training non-educated workers and hiring educated ones, falls, which means that less firms are eager to supply on-the-job training. ${ }^{8}$

\footnotetext{
${ }^{7}$ Note that the quit rate is the same one that we have assumed for the rest of the job matches, $s_{1}$, plus the probability of receiving a skilled job offer for the educated worker employed in unskilled jobs, which is equal to $\theta_{2} q_{2}$.

${ }^{8}$ Under the assumption that the training costs are distributed uniformly between 0 and 1 (the value which we will assume for $y_{1}$, for normalization), $t$ can be interpreted as the proportion of firms training non-educated workers.
} 


\subsection{Simulations}

Given a plausible functional form for the matching function, the model is too complex to be solved analytically. Thus, we proceed as follows. We assume a Cobb-Douglas matching function with constant returns to scale, which seems to fit well the evidence on labour market flows (see Blanchard and Diamond, 1989) and gives rise to the following probabilities:

$$
q_{1}=m\left(\theta_{1}\right)=\theta_{1}^{-\alpha}, \quad m\left(\theta_{12}\right)=\theta_{12}^{-\alpha}, \quad q_{2}=m\left(\theta_{2}\right)=\theta_{2}^{-\alpha},
$$

where $\alpha>0$ is the elasticity of hires with respect to job searchers. Given the exogenous variables $\left(\alpha, r, s_{1}, s_{2}, \beta, z, \kappa, y_{1}, y_{2}, \gamma_{1}\right.$ and $\left.\gamma_{2}\right)$, Eq. (8) determines $\theta_{2}$ and then, Eq. (9) determines $q_{1}$, while Eq. (10) determines $t$. Given $q_{1}$ and $\theta_{2}$, Eqs. (1)-(3), together with the definition of $q_{1}$, determine $u_{1}, u_{2}, v_{1}, v_{2}, e_{1}^{2}$.

We illustrate the implications of the model by means of numerical simulations (Table 3). The parameter values that we used correspond, with some variations, to those used by Mortensen and Pissarides (1998) in their calibration of unemployment in a representative 'European economy'. In particular, we increase the replacement rate, $z$, to be 0.5 , and decrease the separation rate to be 0.3 and 0.1 for unskilled and skilled jobs, respectively. Moreover, $y_{2}$ is assumed to be the double of $y_{1}$, and $\kappa$ is taken to be 1 , namely that $50 \%$ of the labour force is educated. It should be noted that we do not try to calibrate the model to yield 'realistic' values for the endogenous variables (the model is too simple for that task). We rather aim at evaluating the qualitative implications of the model. The first column of Table 3 gives the results for this baseline case: the unemployment rates of non-educated and educated workers are 28.1 and $2.5 \%$, respectively, while $17.3 \%$ of educated workers are employed in unskilled jobs, and the training cost threshold is about 0.21 . In the second column of the table it can be observed that an increase in the relative supply of educated workers, increases both unemployment rates, decreases the proportion of educated workers employed in unskilled jobs but does not affect the training cost threshold. Finally,

\section{Table 3}

Numerical simulations

Parameter values: $y_{1}=1, y_{2}=2, \gamma_{1}=0.25, \gamma_{2}=2, \alpha=0.5, r=0.03$

\begin{tabular}{lccc}
\hline & $s_{1}=0.27, s_{2}=0.18, \beta=0.85, z=0.7$ & & \multicolumn{1}{c}{$s_{1}=0.3, s_{2}=0.2, \beta=0.9, z=0.8$} \\
\cline { 2 - 3 } & $\kappa=0.1$ & $\kappa=1$ & $\kappa=1$ \\
\hline$u_{1}(\%)$ & 19.8 & 28.7 & 32.6 \\
$u_{2}(\%)$ & 1.1 & 6.0 & 8.0 \\
$u(\%)$ & 18.1 & 17.3 & 20.3 \\
$e_{1}^{2}(\%)$ & 17.3 & 12.8 & 20.2 \\
$t(\%)$ & 21.1 & 21.1 & 11.4
\end{tabular}


the third column shows that as separation rates of both types of jobs increase and the bargaining power of educated and the reservation wage of lower educated workers rise, then the unemployment rates of both types of workers increase, the proportion of educated workers employed in unskilled jobs also rises and there are fewer firms willing to supply on-the-job training, in agreement with the stylized facts discussed above.

\section{Concluding remarks}

The causes of unemployment of less-educated workers have relevant welfare and policy implications. From a welfare viewpoint, overeducation and crowding-out of less educated workers can never be a first best solution since potential productivity is not used. In this case, it can be argued that policymakers should stimulate job creation at the top segment of the labour market. However, if any of the other more traditional explanations also count, then policy-makers could better directly focus at the bottom segment of the labour market, for example by introducing subsidies for low-wage jobs. Finally, a conventional wisdom is that when there is crowding-out, there is no need for extra education of low-skilled workers since those workers would occupy unskilled jobs, anyway. Thus, according to the above analysis, an increase in the educational attaintment of the labour force does not always solve the unemployment problem unless other labour market rigidities are reduced.

\section{Acknowledgements}

We are grateful to O. Licandro, C. Pissarides, E. Wasmer, and participants at the EEA ' 99 invited session on Training and Labour Markets: Incentives and Outcomes, for their useful comments.

\section{References}

Acemoglu, D., 1997, Good jobs versus bad jobs: Theory and some evidence. Discussion Paper, no. 1588. CEPR, London.

Alba, A., 1993. Mismatch in the Spanish labour market. Overeducation? Journal of Human Resources 18 (2), 259-346.

Bentolila, S., Dolado, J.J., 1994. Labour flexibility and wages: Lessons from Spain. Economic Policy 10, 233-281.

Blanchard, O., Diamond, P., 1989. The Beveridge curve. Brookings Papers on Economic Activity $1,1-76$.

Brunello, G., 1996. Equilibrium unemployment with internal labour markets. Economica 63, 19-35. 
Dolado, J., Felgueroso, F., Jimeno, J., 1997. The effects of minimum bargained wages on earnings: Evidence from Spain. European Economic Review 41 (3-5), 713-721.

Dolado, J., Felgueroso, F., Jimeno, J., 1999. The causes of youth labour market problems in Spain: Crowding-out, institutions or technology shifts? Mimeo.

Gautier, P.A., 1999. Unemployment and search externalities in a model with heterogeneous jobs and heterogeneous workers. Mimeo. Free University of Amsterdam.

Mortensen, D.T., Pissarides, C.A., 1994. Job creation and job destruction in the theory of unemployment. Review of Economic Studies 61 (3), 397-416.

Mortensen, D.T., Pissarides, C.A., 1998. Taxes, subsidies and equilibrium labour market outcomes, Mimeo.

Muysken, J., Ter Weel, B.J., 1998. Overeducation and crowding out of low-skilled workers. Discussion Paper 98-023, MERIT, Maastricht University.

OECD, 1997. Education at the Glance. OECD, Paris.

OECD, 1998. Employment Outlook. OECD, Paris.

Okun, A., 1981. Prices and Quantities: A Macroeconomic Analysis. Brookings Institution, Washington, DC.

Pissarides, C.A., 1990. Equilibrium Unemployment Theory. Basil Blackwell, Oxford.

Pissarides, C.A., 1994. Search unemployment with on-the-job search. Review of Economic Studies 61 (3), 457-476.

Saint-Paul, G., 1996. Dual Labour Markets. MIT Press, Cambridge, MA.

Thurow, L.C., 1975. Generating Inequality. Basic Books, New York.

Van Ours, J., Ridder, G., 1995. Job matching and job competition: Are lower educated workers at the back of job queues? European Economic Review 39 (9) 1717-1731. 